\title{
Det gamle landskabsnavn Sinlendi eller Sillende
}

Af Wolfgang Laur

I de frankiske kilder kort efter året 800 berettes om et landskab Sinlendi nord for Ejderen, og i Ottars rejsebeskrivelse i Kong Alfreds Orosius nævnes dette samme landskab som liggende mellem Jylland og Hedeby vest for Lillebælt med navnet Sillende. Hvorledes begge disse navneformer hænger sammen i sproglig henseende, hvad landskabsnavnet betyder, og hvilke dele af landet nord for Ejderen det har betegnet, drøftes i følgende artikel.

I sin afhandling Den danske kongemagt ved vikingetidens begyndelse $\mathrm{i}$ Sønderjyske Årbøger 1983 omtaler H. V. Gregersen landskabsnavnet Sinlendi, som det lyder i de frankiske kilder fra 800 -årenes begyndelse, eller Sillende i Ottars rejsebeskrivelse fra dette århundredes slutning. Han mener $i$ en note, at dette navn er uklart og henviser til referatet $i$ bogen af P. Jørgensen om nordfrisernes herkomst.' Jørgensen beskæftiger sig i denne sammenhæng med de gamle indbyggere i Nordfrisland og omtaler det germanske stammenavn Sigulones, som Ptolemaios på sit kort har anbragt ved vestkysten af den jyske halvø, og som den ældre forskning har sammenstillet med Sillende. Efter ældre opfattelse skulle der til grund ligge et germansk *Sihila-, det nuværende tyske $\mathrm{Siel}=$ afløbsgrav, og en sideform *Sigila- efter Vernes lov. Formen Sinlendi i de frankiske rigsannaler opfattes ifølge den mening, som den svenske historiker S. Wadstein har ytret, som en omdannelse, en folkeetymologi. Men Jørgensen fremhæver også, at denne forklaring af vort landskabsnavn ikke er tilfredsstillende, særlig i henhold til formen Sinlendi. Som den svenske sprogforsker R. Ekblom gør han opmærksom på ordet sin- i oldhøjtysk og oldsaksisk og si- i de nordiske sprog. Denne forklaring skal vi komme tilbage til senere.

De danske forskere P. G. Thorsen, G. H. J. Steenstrup og V. la Cour har identificeret landskabsnavnet med ønavnet Sild, særlig med henblik på nogle gamle former som Siland. ${ }^{2}$ Denne forklaring har V. Marstrand optaget i sin bog Aabenraa; Gregersen anforer den i sin note. De nævnte historikere mener nemlig, at det nuværende ønavn oprindeligt 
har betegnet et større område; men også denne teori kritiseres med rette af Jørgensen. Alle gamle og nyere former af ønavnet som f.eks. 1141 (Dipl.dan.1,2,81) de insula Sild eller 1226 (Rep.dipl.1,110) in Sild peger på en gammelnordfrisisk enstavelsesform Sild, en dannelse med et dentalsuffiks til et ord, som svarer til nedertysk Süll, Söll og engelsk sill = tærskel. Fra denne gammelnordfrisiske form afledes ganske normalt Söl' i det nuværende øbomål. Siland er tværtimod en sekundær form. Den findes i senere udtog af diplomer i sammenhæng med Odense klostret, hvis originaler er tabt; men afskrifter af disse breve i den såkaldte Odensebog fra det 15 . århundrede har også den originale form Sild. ${ }^{3}$ Desuden skulle man for et gammelnordfrisisk Siland i dag vente *Silön' eller lignende i det nordfrisiske sprog på øen. Frem for alt er det af geografiske grunde helt usandsynligt, at ønavnet skulle høre sammen med landskabsnavnet Sinlendi.

Som Rigsannalerne fortæller, drog den frankiske hær over Ejderen ind $i$ dette landskab og til et sted ved stranden over for en $\emptyset$, antagelig Fyn, og derfor må vi søge hærens lejrplads ved østkysten af Sønderjylland, men også Ottar beskriver Sillende som liggende vest for Lillebælt.

P. G. Buchloh og I. Skovgaard Petersen har antydet, at navnet Sillende skulle være et oprindeligt Sli-land. ${ }^{4}$ En parallel til sådan en navnedannelse, nemlig en sammensætning af et farvands- eller fjordnavn med ordet land, er ellers ubekendt; højst ønavnet Lolland kan betragtes som en slags semantisk parallel; nemlig som en sammensætning med ordet lå = rende ved kysten. ${ }^{5}$ Følger vi denne navnetydning, så må vi betragte Sillende og især Sinlendi som totalt forvanskede former, og sådanne finder vi egentlig ikke hverken i de frankiske rigsannaler eller $i$ Ottars rejsebeskrivelse.

Men i grunden volder forklaringen af landskabsnavnet Sinlendi/Sillende ingen vanskelighed. Navnet er i etymologisk henseende helt gennemskueligt, og det har allerede tyskerne A. Sach og S. Gutenbrunner, svenskerne E. Ekwall og R. Ekblom og danskeren P. Jørgensen fremhævet, og jeg har sammenfattende behandlet vort landskabsnavn i min bog Die Ortsnamen in Schleswig-Holstein fra 1960 og i mit stednavneleksikon fra $1967 .{ }^{6}$ I det tyske sprog møder vi endnu i vore dage nogle ord, som begynder med et element Sin-, således f.eks. plantenavnet Singrün, som kendes hyppigere under betegnelsen Immergrün, latin: Vinca minor, på dansk vintergrønt. Deraf kan vi slutte, at sin- har den samme betydning som tysk immer = altid. Dertil svarer gotisk sinteins = daglig, en sammensætning med et ord, germansk 
*tina- til lettisk diena, oldslavisk dini, latin dies = dag; men fremfor alt skal i denne sammenhæng nævnes ordet Sindflut i ældre tysk for Sündflut, oldhøjtysk sinvluot, syndflod. Det betyder den store oversvømmelse, og derfor kan vi ikke kun oversætte sin- med altid, men også med stor eller alt omfattende, vældig. Andre eksempler fra oldhøjtysk er simblic $=$ uafladelig, evig eller sinwelbe $=$ rund og fra oldsaksisk $\operatorname{sinhīwun}=æ$ gtefæller, sml. hīwa $=$ hustru eller hīwiski $=$ familie, sinlif = evigt liv, sinnahti = evig nat, sinskōni = evig skønhed, sinweldi $=$ stor skov, sml. tysk Wald, eller sinwell = helt rund.

I nordisk har vi tilsvarende ord, som begynder med si- $\mathrm{i}$ den samme betydning, f.eks. oldnordisk sibylja som navn på en mytologisk ko i betydningen den altid brølende, sibyrða = at lægge bord til bord, d.v.s. skibsside til skibsside eller sifelde $=$ stadig vedvarende, til fella $=$ stadighed. I nydansk kender vi intet ord mere, som begynder med det omtalte element. Oldnordisk si- $\mathrm{i}$ forhold til oldhøjtysk sin- skyldes tabet af det udlydende / $\mathrm{n} / \mathrm{i}$ den senurnordiske periode, sml. tysk un- $\mathrm{i}$ forhold til dansk u- som i unschuldig - uskyldig.'

Det andet led i vort landskabsnavn er en dannelse til ordet land, som vi finder f.eks. i tysk Ge-lände, oldhøjtysk, gi-lenti, ge-lende, eller Elend = elendighed, oldhøjtysk eli-lenti = landsforvisning, fangenskab, fremmede land, elendighed, oprindeligt det andet land, sml. got. aljis $=$ anden. I oldnordisk har vi láglendi $=$ det lave land og i gammeldansk utlænde $=$ det udenfor liggende land. Deraf kan vi slutte, at Sillende i Ottars rejsebeskrivelse gengiver et gammeldansk *Silænde. Müllenhoff og Sach har antaget en betydning »det øde, det ubeboede land «; men det fremgår ikke af navnets etymologi, som vi allerede har set. Betydningen kan omskrives med »det store, det udstrakte land«. Ekblom og Gutenbrunner formoder, at benævnelsen har haft sin oprindelse hos øboerne, f.eks. på Fyn eller Ærø, eller hos søfolk, som kom fra nord eller øst.

Efter beskrivelsen hos Ottar og i de Frankiske Rigsannaler kan vi antage, at Sinlendi/Sillende var, stort set, identisk med det senere og nuværende Sønderjylland. Ottar fortæller, at han havde Jylland - i oldengelsk Gotland - og Sillende på den højre side, inden han kom til Hedeby, og at anglere beboede disse før deres udvandring til Britannien. I de frankiske rigsannaler læser vi: »Nu drog alle saksiske grever ... Harald (d.v.s. Harald Klak) til hjælp over Ejderen i det nordmanniske landskab Sinlendi; derfra rykkede de ud og lejrede sig endeligt den syvende dag i ... ved havets strand «. Angivelsen eller navnet på denne plads savnes i teksterne, og vi læser videre, at Gudfreds sønner opholdt 
sig med flåden på en $\emptyset$ tre mil borte fra fastlandet. Denne $\emptyset$ identificeres med Fyn. ${ }^{8}$ Derfor må vi antage, at den frankiske lejrplads har ligget ved kysten på det østlige Nordslesvig, og for det meste formoder man jo, at navnet Sinlendi også omfatter dette område, men ikke kun Nordslesvig, for efter Ottars rejsebeskrivelse hørte til Sillende også anglernes hjemstavn, før de udvandrede til Britannien. Som det er formuleret i Annalerne, syntes Sinlendi at begynde straks nord for Ejderen.

Dermed har vi sydgrænsen; men hvor lå vort landskabs nordgrænse? Det ser ud til at de fleste er tilbøjelige til at gøre den historiske nordgrænse af Sønderjylland identisk med Sinlendis; men hvor gammel er denne grænse? Navnet Sønderjylland optræder først $i$ anden halvdel af det 13. århundrede, nemlig i titlen på den slesvigske hertug. ${ }^{9}$ Hertugdømmet i sig selv er naturligvis ældre, og de nordslesvigske sysler indtil Kongeåen og Kolding fjord hørte under Knud Lavard. ${ }^{10}$ Men går denne grænse derfor også tilbage til det 10. eller 9. århundrede? I grunden ved vi kun lidt derom. Hvor lå f.eks. nordgrænsen for Gnupas herredømme, som vi er tilbøjelige til at kalde svenskevældet i Hedeby, og hvor lå sydgrænsen for Jellingdynastiets, Gorms rige, inden danskerne under Harald Blåtand erobrede Slieegnen indtil Ejderen?"

Hvis vi identificerer Sinlendi med Sønderjylland, må vi fastslå, at Sønderjylland efter navnet naturligvis skal forstås som den sydlige del af Jylland. I sammenhæng med bispedømmet regnes Slesvig til dette land i de middelalderlige kilder, mens Sillende i den gammelengelske tekst opfattes som et selvstændigt land overfor Jylland. Det hedder her Gotland, og det ser ud som en forveksling med øen Gotland; men det skyldes kun den gammel engelske skrivemåde. Bogstavet 3 svarer til vort $\mathrm{g}$ og udtales $\mathrm{i}$ palatal stilling som et $\mathrm{j}$, og således kunne et oprindeligt $\mathrm{j}$ som i oldnordisk Jótland = Jylland skrives med et 3 .

Deraf kan vi slutte, at landsnavnet Jylland har udvidet sig mod syd og fortrængt det ældre navn Sinlendi. Adam af Bremen skriver i anden halvdel af 1000-tallet, at Jylland begynder nord for Ejderen. Han omtaler flere gange bispedømmer i Jylland, nemlig Slesvig, Ribe og Århus, og det gør også de middelalderlige vestnordiske sagaer. ${ }^{12}$ I tidsrummet mellem Ottars rejsebeskrivelse og Adam af Bremens hamborgske bispekrønike har landsnavnet Jylland fortrængt de ældre Sinlendi eller Sillende på terrænet på det historiske Sønderjylland mellem Kongeåen og Ejderen, og vi kan formode, at det er sket efter erobringen af Sli- og Slesvigegnen under Harald Blåtand. På den anden side skal vi heller ikke overvurdere betydningen af de politiske forhold i denne sammenhæng, således eksistensen af flere delherredømmer. Det var tilfældet $\mathrm{i}$ 
den tid, da Ottar sejlede fra Norge til Hedeby. Men da den frankiske hær drog over Ejderen ind i Sinlendi, og i tiden før eksisterede der antagelig en dansk kongemagt med herredømmet over hele det danske folks daværende bosættelsesområde og over det danske rige fra Ejderen til Skåne.

Her kan vi tilføje nogle sproghistoriske overvejelser. For de sønderjyske dialekters vedkommende er en række af ejendommeligheder typiske, som adskiller dem fra vestjysk i nord. Som bekendt udgør dialektgrænser oftest ikke kun enkelte linier, men et bundt af sådanne. Omrent fra Kongeåen og Kolding fjord til en linie fra Skærbæk til Genner opdager vi et bælte af dialektgrænser, som danner skel mellem vestjysk og sønderjysk. ${ }^{13}$ Dette grænsebælte mellem de to store jyske dialektgrupper falder sammen med det territoriale skel mellem Nørreog Sønderjylland, men naturligvis kun i grove træk. Derfor må vi nu spørge, om denne forskellige udvikling i de to dele af Jylland hænger sammen med hertugdømmets opståen eller om den muligvis er ældre og kunne tyde på en ældre deling af Jylland. Det viser sig, at fornyelserne indenfor de sønderjyske dialekter er yngre. På den anden side bevares de ældre kendetegn; men disse findes også i det nordlige Jylland, sådan at midten af landet har fornyet, mens nord og syd har bevaret dem. ${ }^{14} \mathrm{Af}$ disse overvejelser følger, at vi ud fra dialektskellet mellem vestjysk og sønderjysk ikke kan slutte til en ældre sondring i Jylland end den i højmiddelalderen.

I sammenhæng med navnet Sinlendi, Sillende følger to andre overvejelser. Vi så allerede, at navneformen Sinlendi i de frankiske rigsannaler er vestgermansk, og Sillende genspejler et gammeldansk *Silænde og dermed er nordgermansk, og derfor må vi antage, at Sinlendi var i brug hos sakserne, særlig i Holsten, og *Silænde naturligvis hos danskerne, og at landskabet selv geografisk må søges i naboskabet til Holsten. Hvis nu Sinlendi er en gammelsaksisk form og Sillende gengiver en tilsvarende gammeldansk, kunne det være muligt, at de to hinanden lignende navneformer er nedarvet $i$ begge sprog fra en tid uden større sprogforskel mellem nordisk og vestgermansk på den kimbriske halvø, det vil sige før tabet af det udlydende -n i Sin-. Denne udvikling i nordisk kan dateres mellem 500 og 700 e.Kr.; men en sådan datering af navnet er ikke helt sikker, for det kan også være lidt yngre, overtaget fra det ene sprog til det andet, for man vidste jo sikkert også hos sakserne, at et med nordisk si-begyndende ord svarede til et med sin- i det saksiske sprog.

Et andet spørgsmål står i sammenhæng med navnets betydning. 
Den blev fastslået som »det store, det udstrakte land«; men hvis vi nu antager, at det har ligget $\mathbf{i}$ det senere Sønderjylland eller er identisk med det, bør vi ikke glemme, at den største landmasse faktisk udgøres af Nørrejylland. Gutenbrunner tyder vort navn som »storland, continens terra«, det vil sige »fastlandet«, nemlig set fra de søfarendes synspunkt, som sejlede til Hedeby og videre og ingen gennemsejling fandt her, så de måtte køre over land til Nordsøen; ${ }^{15}$ men på den anden side kan vi spørge, om vi har paralleller til en sådan navngivning.

Vi har allerede set, at navnet Jylland oprindelig ikke omfattede det område, som kaldes Sinlendi, Sillende i det 9 . århundrede; men siden 1000-tallet rakte Jylland, som vore kilder fortæller, mod syd til Ejderen. Landsnavnet Jylland har altså udvidet sig mod syd. Kunne vi da ikke forestille os, at dette navn ved dets opstån har betegnet et mindre område? Det betyder »jydernes land «, og som jyder forstod man i folkevandringstiden og i de ældre perioder ikke hele halvøens befolkning, men kun en stamme mellem flere, ${ }^{16}$ så vi kan formode, at Jylland $\mathbf{i}$ begyndelsen kun betegnede disse jyders stammeområde. Sinlendi kunne da have været navn for et landskab med en større udstrækning end det senere Sønderjylland, også mod nord. Men her dukker atter spørgsmålet om stammeområdet for disse ældste jyder op. Hvis vi nemlig antager, og det er også kun en antagelse, at det har ligget nordvest for Olgerdiget, så er vor formodning uholdbar, for dermed ligger jo jydernes sydgrænse midt i Sinlendi.

I den middelalderlige engelske overlevering træffer vi desuden på et andet navn for egnen omkring Slien og Slesvig- Hedeby. Således skriver Ethelwerd i sin krønike fra tiden efter 974, at Anglia vetus, d.v.s. "anglernes gamle land«, ligger mellem sakser og jyder - inter Saxones et Giotos - og med en hovedby, som kendes under navnet Sleswic hos sakserne og Haithaby hos danskerne. Med det latinske udtryk Anglia vetus $=$ anglernes gamle land betegner Ethelwerd anglernes bosættelsesområde før deres udvandring til England; men muligvis ligger bag denne formulering også landskabsnavnet Angel, som var kendt på denne tid i England. Om Sillende og iglanda fela = »mange øer« beretter Ottar, som vi har set, at on paem landum eordodon Engle aer hi hiðer on land coman $=$ »i disse lande boede anglerne, før de kom her $i$ landet«. Ottars og Wulfstans beretninger om deres rejser findes i en beskrivelse af Europas norden, som er tilføjet som tillæg til den gammelengelske oversættelse af den senantikke verdenshistorie, som har spanieren Orosius til forfatter. Oversættelsen og tillægget kendes under navnet Kong Alfreds Orosius. Deri hedder det om landet 
omkring Hedeby og Slien: pe mon het Ongle= disse kalder man Angel; men den samme form er omtrent hundrede år ældre og findes $\mathrm{i}$ det kendte gammelengelske kvad Widsid. Her læser vi, at Offa weold Ongle Alewih Denum = Offa herskede over Angel, Alewih, d.v.s. Ølvir, over danerne. ${ }^{17}$ Mærkværdigt er nu i denne sammenhæng, at Widsid i alle andre tilfælde omtaler folkestammer og deres konge, f.eks. franker, hunner, daner, men ikke lande. Kun i et tilfælde finder vi ikke stammenavnet, nemlig anglernes, oldengelsk Engle. Med det omtalte vers begynder overleveringen om anglerkongen Offa og dennes kamp med myrgingerne eller svaberne ved Fifeldor, antagelig Ejderen, og et af de sidste vers har også stammenavnet Engle, men i sammenhæng med kongen og dens herskabsområde kendes her landskabsnavnet Ongel $=$ Angel.

G. P. Buchloh har henvist til, at i den ældre germanske overlevering findes der overvejende stammenavne, navne for stammer, for nationes, og ikke for landene, for regiones. Fiktionen i det omtalte gammelengelske digt er, at sangeren Widsid har besøgt omtrent alle verdens bekendte folkestammer og deres herskere. Men derved taler han kun om deres navne og ikke om navnene på deres lande. Kun anglernes gamle land er en undtagelse. Her findes landets navn, nemlig Ongel. ${ }^{18}$ Buchloh slutter deraf, at dette land med navnet Angel, Ongel har spillet en stor rolle indenfor dette germanske område, at det har været et centrum for færdsel, handel og for kultur. Man mener jo også, at anglerne har været hovedstamme inden for det såkaldte Nerthusforbund, ${ }^{19}$ og således var det et centralt landskab ikke kun i germansk tid, men også ved vikingetidens begyndelse, ved Hedebys oprindelse.

I denne sammenhæng skulle spørgsmålet om den angelske overlevering og dens centrale stilling inden for den danske middelalderlige tradition og historieskrivning undersøges påny. Muligvis betegnede Angel oprindeligt et større område end kun landskabet mellem Slien og Flensborg Fjord. Efter Erdmann og Kr. Hald drejede det sig oprindeligt om et navn for Slien, og anglernes stammenavn - latin: Anglii, gammelengelsk engle, germ. *Anglīz, er en afledning deraf i betydningen beboere, indbyggere af Angel, og i denne sammenhæng bør vi også spørge efter forholdet mellem landskabsnavnet Angel og Sinlendi i 800-tallet. Beskrivelsen i Kong Alfreds Orosius kunne man tyde således, at Sinlendi er et mere omfattende begreb end Angel; men helt sikkert er det ikke.

Vi kan sammenfatte: navnet Sinlendi, Sillende har vel betydet det store, det udstrakte land; men ud fra etymologien og betydningen kan 
vi intet nøjere sige om dette landskabs beliggenhed. Sproglige kriterier kunne tale for en højere alder; det kunne gå tilbage til folkevandringstiden. Efter kildernes vidnesbyrd brugtes det i 800-tallet, og det gjaldt for landet nord for Ejderen og det østlige Nordslesvig; men om nordgrænsen over for Jylland kan vi intet videre sige. I Ottars rejsebeskrivelse står begge navne Jylland og Sillende side om side, og det sidste opfattes ikke som del af Jylland. Desuden kan vi heller ikke sige noget nøjere om forholdet mellem navnene Sinlendi, Sillende og Angel. Hvis den frankiske hær gik over Ejderen og derved kom ind i Sinlendi og drog til et sted ved østkysten af Nordslesvig, så måtte vi naturligvis opfatte Angel som en del af Sinlendi; men stemmer denne tolkning overens med sprogbrugen i Kong Alfreds Orosius, og står begge navne ved siden af hinanden i denne kilde? Vi kunne også formode, at Sinlendi er opstået efter anglernes udvandring til England og se det i sammenhængen med indskrænkningen af navnet Angel fra anglernes stamområde til landskabet mellem Sli og Flensborg Fjord. Antagelig i det 10. århundrede gik navnet Sinlendi, Sillende af brug, og dets område regnedes nu til Jylland.

\section{HENVISNINGER}

I teksten er der foran rekonstruerede stednavneformer sat en stjerne $\left(^{*}\right)$.

1. P. Jørgensen: Über die Herkunft der Nordfriesen. Det Kgl. Danske Videnskabernes Selskab. Historisk-Filologiske Meddelelser, Bd XXX, Nr. 5, København 1946, s. 38 39.

2. P. G. Thorsen: De med Jydske Lov beslægtede Stadsretter for Slesvig, Flensborg, Aabenraa og Haderslev, Kjøbenhavn 1855, s.5 og V. La Cour: Sønderjyllands Historie I, København 1930 - 31, s.149.

3. W. Laur: Die Ortsnamen in Schleswig-Holstein. Gottorfer Schriften Bd 6, Schleswig 1960, s.355 - 356 og Historisches Ortsnamenlexikon von Schleswig-Holstein. Gottorfer Schriften Bd 7, Schleswig 1967, s.198.

4. P. G. Buchloh: Angeln - Regio oder Natio? - Eine philologische Betrachtung. Offa 37 (1980), Festschrift für Hermann Hinz, s.360 - 365 og I. Skovgaard Petersen: Oldtid og vikingetid. Danmarks historie Bd 1, Andet oplag, København 1977, s.109.

5. B. Jørgensen: Danske Stednavneleksikon. Øerne øst for Storebælt, København 1981, s.77.

6. W. Laur: Die Ortsnamen in Schleswig-Holstein, s.361 - 362 og Historisches Ortsnamenlexikon, s.189.

7. A. Noreen: Altisländische Grammatik 4 , Halle 1923, s.221 og Geschichte der nordischen Sprachen ${ }^{3}$, Straßburg 1913, s.14 og Johs. Brondum-Nielsen: Gammeldansk Grammatik II $^{2}$, Konsonantisme, København 1957, s.57. 
8. Quellen zur karolingischen Reichsgeschichte 1. Teil. Die Reichsannalen, neubearb. v. R. Rau. Ausgewählte Quellen zur deutschen Geschichte des Mittelalters Bd V, Darmstadt 1955, s.106 - 107.

9. W. Laur: Namenkundliche Miszellen. 1. Schleswig als Landesname. Beiträge zur Schleswiger Stadtgeschichte 8 (1963) s.59 - 62.

10. H. Windmann: Schleswig als Territorium. Quellen und Forschungen der Geschichte Schleswig-Holsteins 30. Bd, Neumünster 1954, s.42 - 50.

11. W. Laur: Zur Schwedenherrschaft in Haithabu und neue Überlegungen zur Frühgeschichte des Schleswiger Raumes. Beiträge zur Schleswiger Stadtgeschichte 28 (1983) s.9 - 25 .

12. Adam von Bremen, Hamburgische Kirchengeschichte ${ }^{3}$, hrsg. v. B. Scheidler, Hannover u. Leipzig 1917, s.230 og O. Scheel, P. Paulsen: Quellen zur Frage SchleswigHaithabu, Kiel, s.125.

13. V. Bennike, M. Kristensen: Kort over de danske folkemål, København $1898-1912$, $\mathrm{K}, 1,6,19,21,22,25,29,32,34,36,40,45,47,49,50,51-53,56-58,74-75,77-78,85$, $86,96$.

14. H. Löffler: Probleme der Dialektologie. Eine Einführung, Darmstadt 1977, s.149 153.

15. W. Laur: Die Ortsnamen in Schleswig-Holstein, s.361 - 362.

16. S. Gutenbrunner: Die Herkunft und Ausbreitung der Dänen: S. Gutenbrunner, H. Jankuhn, W. Laur, Völker und Stämme Südostschleswigs im frühen Mittelalter. Gottorfer Schriften Bd 1, Schleswig 1952, s.109 - 111, E. Schwarz: Germanische Stammeskunde, Heidelberg 1956, s. 115 - 1116, W. Laur: Nerthuskult und Nerthusbund. Jahrbuch des Angler Heimatvereins 26 (1962) s.28 - 44 og H. Neumann: Olgerdiget.

17. W. Lange: Anglische Dichtung: H. Jankuhn, Die römische Kaiserzeit und die Völkerwanderungszeit. Geschichte Schleswig-Holsteins 2.Bd. Von der Bronzezeit bis zur Völkerwanderungszeit, Neumünster 1979, s.329 - 331.

18. P. G. Buchloh: Angeln - Regio oder Natio? sml. 4.

19. W. Laur: Nerthuskult und Nerthusbund. 
